\title{
Presença dos indígenas de Mato Grosso na internet e na produção de mídias: militância, sustentabilidade e memória
}

Presence of Indigenous peOple from Mato Grosso on the INTERNEt AND IN THE PRODUCtion OF MEDIA: MILITANCY, SUSTAINABILITY AND MEMORY

\section{Naine Terena de Jesus}

Doutora em Educação, mestre em Artes e graduada em Comunicação Social com habilitação em Radialismo. É bolsista de pós-doutorado no Programa de Pós-Graduação da Universidade Federal de Mato Grosso (UFMT). E-mail: naineterena@hotmail.com

E-mail: biacpd@pucrs.br

\section{Kátia Morosov Alonso}

Prof. dra. do Instituto de Educação da Universidade Federal de Mato Grosso (UFMT). Coordenadora do grupo de pesquisa Letece - Laboratório de Pesquisas em Tecnologias de Informação e Comunicação na Educação. E-mail: katia@ufmt.br

\section{Cristiano Maciel}

Docente do Instituto de Computação da Universidade Federal de Mato Grosso (UFMT). Diretor da Fundação Uniselva e supervisor do grupo de pesquisa Letece - Laboratório de Pesquisas em Tecnologias de Informação e Comunicação na Educação. E-mail: crimac@gmail.com

Recebido em 6 de março de 2015. Aprovado em 30 de junho de 2015.

\section{Resumo}

Este artigo apresenta o levantamento de dados realizado na internet e em produção audiovisual para identificar perfis em redes sociais, blogs, páginas e mídias produzidas pelos povos indígenas de Mato Grosso, com uma breve análise dos conteúdos e da presença indígena na internet e na produção de mídias. Este artigo faz parte de um projeto de pesquisa que visa a refletir sobre a presença das tecnologias de informação e comunicação no contexto da educação dos povos indígenas de Mato Grosso. Palavras-chave: Povos indígenas. Internet. Cultura. Tecnologias. 


\section{Abstract}

This article presents the data survey conducted on the internet and audiovisual production to identify profiles on social networks, blogs, pages and media produced by the indigenous people of Mato Grosso, Brazil, with a brief analysis of the content and indigenous presence in the internet and in media production. This article is part of a research project that aims to think the presence of information and communication technologies in the context of the education of the indigenous people of Mato Grosso.

Keywords: Indigenous people. Internet. Culture. Technology.

\section{Introdução}

A internet é um espaço cada vez acessível, e diante disso vemos cada vez mais a presença de diferentes pessoas, com as mais distintas intenções, ou ainda, como escreve Matuk (2008, p. 481), "estamos sendo especialmente afetados pela crescente digitalização dos discursos e consequente virtualização das nossas entidades". Nessa vertente, vemos cada vez mais a produção de mídias, como CD, DVD e livros virtuais, devido ao surgimento de softwares de edição e criação ${ }^{1}$ e também à popularização de aparelhos que facilitam a captação de imagens e sons, como os telefones celulares.

Diante desse crescente fenômeno, investigamos a presença de indígenas do estado de Mato Grosso na internet e na produção de conteúdos em audiovisual, com a intenção de verificar a virtualização da entidade indígena² .

Cabe ressaltar que em Mato Grosso existem hoje cerca de 40 povos indígenas com idiomas diferenciados e que vivem espalhados pelo território no estado. Parte dessas populações está bastante próxima de algumas cidades e mais próximas, ainda, de fazendas e do agronegócio. Elas têm um número expressivo de jovens e adultos estudando Curso Superior e, em virtude disso, têm tido cada vez mais acesso às diferentes tecnologias de comunicação e informação, assim como a embates sobre a questão territorial e a

1 Embora quando se trate da produção audiovisual no Brasil, existe a constante reclamação de pequenos investimentos.

2 Quando citamos a entidade indígena, pensamos na representação virtual que se tem feito dos povos indígenas e por isso, excluímos da pesquisa perfis individuais, pois estes têm representado em muitos casos apenas aquela pessoa, que com alguma frequência posta informações acerca de seus povos ou culturas. A ideia então é ver como perfis e páginas coletivas abordam a cultura indígena e, no caso do audiovisual, quais temáticas são retratadas nos vídeos. 
degradação do meio ambiente. Embora não tenhamos registros mais concretos, nas visitas que fizemos a aldeias indígenas, notamos a presença da internet ${ }^{3}$ e também de energia elétrica.

\section{Metodologia}

O levantamento de informações sobre a presença indígena na internet e a produção de conteúdos foi realizado através de buscadores da internet, páginas de instituições indigenistas, rede social, Facebook, e informações de indígenas que estão na rede virtual de contatos dos pesquisadores.

O filtro utilizado para selecionar as iniciativas, que fariam parte da análise, foi o tipo de presença, sendo consideradas as que estavam relacionadas a questões políticas, proposição de divulgação cultural e, ainda, de comercialização de produtos advindos de comunidades e/ou indivíduos indígenas. Os perfis individuais do Facebook não foram alvo de análise, embora se apresentem em números bastante expressivos e muitos deles se identificam como indígenas, inserindo cotidianamente informações visuais e textuais referentes à temática indígena.

A partir desses dados foram mapeadas 40 iniciativas de apropriação de mídias e tecnologias de comunicação e informação, cujos dados foram divididos da seguinte forma:

- Audiovisual: Lista que contém o nome dos realizadores em audiovisual indígena no estado de Mato Grosso. Coletamos o nome dos realizadores, povo de origem e o nome da produção audiovisual;

- Blogs: Levantamento de blogs com temática indígena pertencente a povos do estado de Mato Grosso, verificando se tais páginas estão atualizadas ou não, e se são produzidas individualmente ou em coletivo;

- Perfis no Facebook: Verificação da presença virtual de povos indígenas, destacando perfis de associações, militância, informação e contexto indígena.

Na observação dos conteúdos levantados, criamos colunas para o tipo de alimentação: individuais e coletivos, que se caracterizam pela descrição da produção/manipulação das tecnologias como sendo gerados por apenas um indivíduo, ou coletivo, para aqueles realizados com mais indivíduos, sendo esse caracterizado como coletivo indígena ou coletivo misto (realizado com não indígenas); Atualizado/desatualizado, no caso das

3 Não foi possível estimar a porcentagem de territórios com acesso à internet. 
produções em audiovisual atualizadas diz respeito àquelas produzidas nos últimos 5 anos, e no caso das páginas do Facebook, sites e blogs, consideramos a manutenção dos últimos 4 meses como "atualizado".

O critério para avaliação do conteúdo coletado se caracteriza pelo fluxo de informações e pelas trocas estabelecidas entre produtor de conteúdos e público final, aquele que acessa às informações. Dessa forma, analisamos a frequência de alimentação ou produção, o conteúdo abordado, as possibilidades de interação do público com as produções, a participação de outras pessoas das comunidades e/ou etnias, características estéticas da página (se relacionam com elementos da cultura tradicional) e a interação dos públicos interno e externo com as produções.

\section{Indígenas, a rede mundial de computadores e as mídias}

De acordo com Pereira (2007), no Brasil, os primeiros registros da participação indígena na internet são do ano 2001, e de lá para cá essas formas de comunicação na rede se tornaram blogs, comunidades virtuais e portais. Já a produção audiovisual tem uma produção mais expressiva na década de 1980, através de projetos como o vídeo nas aldeias e a forte presença de Mário Juruna em Brasília, que com um gravador iniciava um ciclo de registros de falas de políticos brasileiros e de suas promessas.

Ao realizar a observação do material coletado, surge o que Matuk (2011, p. 484) trata como sujeito cíbrido, "aquele que tem a forma híbrida entre o físico e o eletrônico", destacando que esse contexto digital cria potencialidades linguísticas e identitárias que permitem aos seres humanos "experienciar, comunicar e representar em níveis até agora insuspeitos" (Ibidem, p. 11). No caso da presença indígena, verifica-se que as tecnologias de comunicação e informação são importantes elementos para as experiências e representação, capaz de dar aos indivíduos que as operam a oportunidade de explorar essas potencialidades, que podem ser transportadas do real para o virtual e ser visualizadas nos pontos mais longínquos do planeta.

No caso das apropriações indígenas observadas, vemos que essa presença no mundo virtual e tecnológico vem sendo utilizada como uma forma de militância para combater as investidas contra os povos tradicionais e de divulgação da cultura desses povos, seja como forma de sair da invisibilidade, seja como uma maneira de se buscar sustentabilidade através da comercialização de artefatos, dos próprios filmes produzidos, que podem ser encontrados no YouTube ou adquiridos em páginas da internet e de grupos culturais diversos. Para Matuk (2011, p. 488), a internet oferece um local onde grupos tradicionalmente excluídos são capazes de articular suas vozes e ser ouvidos: 
Netizens ou cibercidadãos adquirem o potencial de recriarem tanto o espaço real como o espaço virtual que eles ocupam. A possibilidade de produzir e sustentar narrativas identitárias, pontos de vista, articulações políticas, no ambiente virtual, torna possível uma melhor negociação das identidades da vida real.

$\mathrm{O}$ autor ressalta que o ciberespaço se tornou um espaço privilegiado para a fala individual e coletiva de minorias marginalizadas, o que no levantamento realizado transparece de forma bastante objetiva o motivo, pelo qual esses grupos estão presentes no ambiente virtual.

Já com relação à produção audiovisual indígena, Nichols (2005) afirma que os documentários nos dão a capacidade de ver questões oportunas que necessitam de atenção. Vemos visões (fílmicas) do mundo, que abordam questões sociais e atuais, problemas recorrentes e soluções possíveis: "o vínculo entre o documentário e o mundo histórico é forte e profundo. $\mathrm{O}$ documentário acrescenta uma nova dimensão à memória popular e à historia social" (Ibidem, p. 27). Este autor argumenta que os documentários podem conceber o mundo da mesma forma que um advogado representa os interesses de um cliente: colocam diante de nós a defesa de um determinado ponto de vista ou uma determinada interpretação das provas e os vídeos indígenas não fogem a esta característica. O cineasta indígena oferece ao espectador a sua verdade, a sua visão e a visão do seu povo, acerca da forma de vida em que vivem, ou defendendo a autonomia e o modo de vida diferenciado.

Esse tipo de produção se enquadra no referencial apresentado por Mesquita (2003) de que a partir da metade da década de 1980 surgiram no Brasil diferentes produções documentais focando grupos sociais e populações marginalizadas. Segundo a autora, foi nesse período que as minorias tiveram acesso aos microfones, para fazer ouvir as vozes daqueles sobre os quais pesava uma identidade social imposta, abstrata, estereotipada ou identidade alguma, entrando em cena a população carcerária, os moradores de rua, pivetes, mendigos, prostitutas, sobreviventes do lixo, e também, os indígenas.

\section{Mídias indígenas: cenário do mapeamento}

Verificamos que pelo menos 15 realizadores indígenas de Mato Grosso, de forma individual ou orientados por um projeto não governamental, produziram e produzem registros de elementos da cultura de seus povos através do audiovisual.

Esses vídeos funcionam como mecanismos de registro de memória e também como divulgador da cultura indígena, já que alguns deles ganharam projeção e repercussão internacional, além de ter seus diretores premiados em festivais, como é o caso do 
cineasta indígena Takumã Kuikuro, com o recente As hiper mulheres ${ }^{4}$ (2011). A direção desse longa-metragem é compartilhada com não indígenas, e o documentário tem agradado público e crítica, recebendo pelo menos três premiações 5 . Os perfis dos cineastas indígenas localizados apontam que estão bastante ativos, com produções recentes (entre o período de 2000 a 2013). Outro elemento a ser observado é que a grande maioria dos produtores audiovisuais mapeados pertence a povos que vivem na região do Parque Nacional do Xingu e ao povo Xavante. Os filmes na maioria das vezes são documentários e trazem aspectos mais relacionados a rituais, mitos, festas e cotidiano. $\mathrm{O}$ fato de ser, em grande parte, vinculados a projetos financiados por instituições de apoio a causa indígena, ou instituições voltadas para a capacitação em audiovisual, também é um dado interessante, pois, verifica-se que o investimento para a realização dessas produções tem sido eficiente.

As obras, que pudemos ter acesso, têm sido produzidas em HD ou FULL HD, com edições de cortes secos, dando o poder da narrativa aos próprios indígenas, dispensando a presença da narração/voz off para que seus protagonistas conduzam a história.

No processo de execução, essas obras contam com a presença da comunidade, e essa participação causa um efeito interno bastante interessante, como se pode observar no vídeo Uma casa, uma vida (2013). Neste há uma narrativa da entrada de casas de alvenaria em terras tradicionais Xavante, através do projeto Minha Casa, Minha vida, implementado pelo governo federal em parceria com as esferas estadual e municipal em diferentes regiões do país. $\mathrm{O}$ vídeo foi produzido simultaneamente a um projeto denominado Tiba'Uwe, idealizado pelo produtor cultural Alexandre Lemos, que propôs a construção de duas casas utilizando a técnica de bioconstrução. Para a produção do documentário, jovens Xavante foram capacitados e se envolveram na realização do vídeo que foi projetado para as comunidades envolvidas e outras aldeias deste povo.

O resultado do trabalho trouxe uma reflexão interna quanto às residências tradicionais indígenas, com a entrada de projetos governamentais de moradia. Nesse sentido, pode-se observar que a produção com autoria e participação dos próprios indígenas tem uma grande repercussão com o público externo, pois ele tem a possibilidade de apreender um pouco mais sobre a cultura indígena, e o público interno - os próprios Xavante, ao se envolver com a produção audiovisual, começam a refletir sobre sua existência,

4 Este curta conta a história de um velho que ao temer a morte da esposa idosa pede que seu sobrinho realize o Jamurikumalu, o maior ritual feminino do Alto Xingu (MT), para que ela possa cantar mais pela última vez. As mulheres do grupo começam os ensaios enquanto a única cantora que de fato sabe todas as músicas se encontra gravemente doente.

5 Festival Olhares Brasil: Prêmio do Público, Prêmio da Crítica e Prêmio Olhar na categoria Melhor Filme; Melhor documentário As hiper mulheres na entrega do $10^{\circ}$ prêmio Fiesp/ Sesi-SP de cinema 2014. 
identidade, educação tradicional e o uso das tecnologias em prol do movimento de memória e resistência.

\section{Presença na rede mundial de computadores}

A presença indígena na internet é marcada por diferentes temáticas. Os blogs e sites são relacionados, em grande parte, a associações e entidades ligadas às comunidades e povos, têm o intuito de difundir as ações que elas realizam e seus parceiros, mantendo diversas informações sobre a etnia a quem estão relacionados.

Da mesma forma que os sites e blogs atuam no universo virtual, as páginas de Facebook se multiplicam a cada dia através de perfis individuais ou que representam etnias e instituições ligadas aos grupos étnicos. Verifica-se uma grande presença de militância, divulgação cultural e tentativa de comercialização de diferentes produtos ou grupos culturais que realizam danças, cantos e outras atividades ligadas às atividades lúdicas ${ }^{6}$.

Um exemplo é a Associação Terra Indígena Xingu (Atix) ${ }^{7}$, que reúne vários povos do Xingu, com uma expressiva inserção no Facebook. Nesta rede eles divulgam assuntos relacionados às ações realizadas para e com os povos Xinguano, e a interação por parte desses povos na página é bastante intensa. Além de comentar, compartilhar e explicar postagens, dentre os assuntos mais abordados estão a divulgação de atividades de sustentabilidade, venda de artes, reuniões, ações das escolas Xinguana e eventos abertos ao público. Ainda no Facebook, vemos a página da aldeia Bakalana, do povo Umutina. Os amigos e visitantes dessa página podem conhecer um pouco mais do dia a dia da comunidade, localizada na terra indígena Umutina em Barra do Bugres (MT).

Os alimentadores da página deixam sempre evidente o pertencimento étnico e o orgulho de ser Umutina. Sob esse ponto de vista, as postagens quase sempre trazem imagens da infância e a educação Umutina, festas, residências e destacam a exuberante natureza. Também fazem algumas investidas comerciais, como a divulgação e comercialização da pimenta produzida por um membro da comunidade.

De uma forma geral, as páginas mantêm uma característica estética associada ao povo, ou à temática indígena, trazem fotografias, grafismos, frases de efeito. $\mathrm{O}$ braço comercial dessas iniciativas também merece observação, pois, em virtude do grande interesse que a cultura indígena desperta nos não indígenas, a presença nas redes para comercialização é um fato que vem se consolidando cada vez mais.

6 Principalmente quando transportadas para o ambiente do não indígena.

7 Para mais informações acesse: <www.facebook.com/atixxingu?fref=ts $>$. 
No que diz respeito à geração de renda e economia, têm se observado nos últimos tempos a inserção do comércio virtual e o estudo de conceitos como economia criativa, economia solidária e comércio justo. Essas tendências aspiram a chegar nessas comunidades como formas de melhorar a visibilidade da produção e de valorização e valoração das artes indígenas em suas diferentes esferas.

Nota-se também o intenso debate sobre os direitos intelectuais e coletivos sobre a produção indígena. A presença virtual tem fomentado e despertado nessas comunidades o interesse em saber os limites e desafios da comercialização do seu patrimônio imaterial e material, de forma que possam obter lucro e respaldar-se dos direitos que têm sobre esses patrimônios. A rede de computadores e, sem dúvida, as redes sociais têm dado visibilidade a esse tema, devido à presença de negociações polêmicas ocorridas nos últimos tempos.

A necessidade de se inteirar desses e de outros temas que envolvem a cultura indígena tem obrigado os povos a compreender e manipular cada vez mais as tecnologias de comunicação e informação e melhorar o acesso à informação através delas. Para Matuk (2011), será cada vez mais indispensável a alfabetização digital para questões de articulação política, de presença social, de proposição cultural, de inovação estética, de ordenação jurídica, de criação identitária no futuro imediato. No entanto, ressalta que será preciso uma estrutura forte para que se possa atuar politicamente e projetar a voz nessa dimensão de forma correta, sabendo prever as crises diante de proposições e denúncias.

Essa intensa presença nos leva a pensar sobre o grande impacto que as tecnologias causaram na educação indígena, recebida no seio das comunidades e como este extenso contato mudaria as relações com rituais e modos de vida de cada etnia, sugerindo que tais povos estariam passando pelo processo de assimilação, hibridação, homogenização ou ainda, se podemos assim dizer, de globalização. Também propõe uma reflexão sobre o comportamento: a forma como as vozes estão sendo projetadas (MATUK, 2011). No entanto, os cenários apresentados (homogeneização, total assimilação) deixam de ser a realidade, já que, mesmo tendência em direção a homogeneização global, existe a fascinação com a diferença e com a mercantilização da etnia e da alteridade (HALL, 2002).

Para este autor, poderíamos pensar em uma articulação do global com o local, ao invés de uma substituição total, de um por outro. Essa observação de Hall é pertinente quando se trata da temática em questão, pois, vemos que ao mesmo tempo que as inserções na internet por parte dos membros dessas comunidades indígenas criam novas identificações globais, também fomentam as identificações locais.

A apropriação das redes para a afirmação da identidade étnica abre espaço para a percepção de sujeitos que reafirmam sua origem/localidade ao mesmo tempo que se engajam em ferramentas externas (a rede de computadores) e interagem com a identificação 
global, através da linguagem e das plataformas que estão à disposição. Nesse sentido, Hall (2002) não desqualifica o sujeito que promove essa transição entre a identidade global com a local, pois afirma que:

As sociedades de periferia têm estado sempre abertas às influências culturais ocidentais, e agora, mais do que nunca. A ideia de que esses são lugares fechados - etnicamente puros, culturalmente tradicionais e intocados até ontem pelas rupturas da modernidade - é uma fantasia ocidental sobre a alteridade: uma fantasia colonial sobre a periferia, mantida pelo Ocidente, que tende a gostar de seus nativos apenas como puros e de seus lugares exóticos apenas como intocados (p. 79-80).

Dessas reflexões, podemos dizer que existe a reafirmação, ou o "reforçamento", como escreve o autor, da identidade local, até mesmo como uma manifestação política contra o "racismo cultural", e no caso brasileiro, o desejo de tornar os indígenas cidadãos civilizados e integrados à sociedade ${ }^{8}$. A afirmação da etnicidade indígena é uma forma de protesto e também de resistência, ainda que muitos desses indivíduos que mantêm as páginas, ou instituições vinculadas aos povos, não estejam em território indígena.

No levantamento de informações, não foi possível identificar o local exato onde residem as pessoas que alimentam as páginas, perfis e produzem os vídeos, inclusive pelo fato de que a informação acerca da localidade indígena não é identificada pela própria internet em alguns casos. Sabemos que alguns cineastas indígenas residem em territórios pertencentes aos seus povos e outros, em cidades próximas; observa-se que nos perfis do Facebook, a localização apresentada é sempre de uma cidade próxima à área indígena, e nos blogs e páginas da internet essa identificação também foi precária.

É importante delimitar esse espaço onde se encontram os usuários dessas tecnologias, para que possamos abordar a forte presença da afirmação de pertencimento à etnia e a diversidade nas produções pesquisadas, assim como o senso comum, que diria que os indivíduos que estão afastados das áreas tradicionais, os chamados "mestiços" e aqueles que dominam as diferentes tecnologias (como telefone celular), deixam de ser indígena ou de pertencer a determinados povos, mesmo que afirmem o pertencimento em seus perfis, filmes e páginas da internet ${ }^{9}$. O estigma do índio que não é índio, porém, se dissolve

8 A integração dos povos indígenas à sociedade nacional permeou diferentes governos e mesmo com a Constituição de 1988, que garante o direito de vida diferenciado aos povos indígenas, existem diferentes investidas com a intenção de descaracterizar o "ser indígena" e, dessa forma, criar situações para que sua identidade étnica deixe de ser um dos principais pilares dos direitos constitucionais.

9 Verificamos que a produção mapeada conta com um número de pessoas que estão em trânsito cidade/aldeia, e por isso dedicamos alguns parágrafos para abordar o senso comum. 
diante das informações apresentadas pela Fundação Nacional do Índio (Funai) com base na Lei n. 6.001/73 (Estatuto do Índio) e do que Hall (2002) aponta como tradução.

A Funai diz que o sujeito no Brasil é considerado indígena através de duas situações: a autoidentificação e o reconhecimento por parte de algum povo originário brasileiro, independente da localização onde está no momento.

Existe uma possibilidade para o quadro que transita entre o retorno às raízes e a homogeneização - a tradução:

Este conceito descreve aquelas formações de identidades que atravessam e intersectam as fronteiras naturais, compostas por pessoas que foram dispersadas para sempre de sua terra natal. Essas pessoas retêm fortes vínculos com seus lugares de origem e suas tradições, mas sem a ilusão de um retorno ao passado (Ibidem, p. 88).

Esse autor salienta que para os indivíduos nessa condição e no caso dos indígenas, que se afastam de suas aldeias, é necessário negociar com as novas culturas que vivem, sem simplesmente ser assimilados por elas e sem perder completamente suas identidades, pois: "carregam os traços culturais, das tradições, das linguagens e das histórias particulares pelas quais foram marcadas" (Ibidem, p. 88).

Dessa maneira, ao abordar a linha de produção, presentamos o fenômeno que cresceu nos últimos anos, a mobilidade do sujeito indígena entre os territórios e as cidades.

\section{Considerações finais}

Este artigo apresentou o resultado de um levantamento da produção de indígenas de Mato Grosso na internet e em mídias (especificamente o audiovisual), com o intuito de observar como ocorre a presença e apropriação desses povos a essas tecnologias. No que diz respeito à internet, tem se tornado um espaço de amplo debate, divulgação e reafirmação da cultura indígena, assim como um local acessível para a militância e denúncias.

Já a produção audiovisual ganha espaço em mostras de vídeos, festivais de cinema sendo um suporte interessante para educadores que querem utilizar tais materiais para apresentar os diferentes povos indígenas. Tanto o conteúdo disponibilizado on-line como produzido em mídias, como DVD, têm características parecidas em sua produção, pois de uma forma geral, pode-se observar, a partir do mapeamento realizado, que o acesso às tecnologias de comunicação e informação permitiu que a população indígena esteja mais presente e dê uma maior visibilidade a sua existência, já que o número de pessoas que se inter-relacionam e se conectam independente de suas localidades tem aumentado cada 
vez mais, tornando esses espaços propícios para sua reafirmação identitária e cultural, promovendo a sustentabilidade por meio da apresentação dos elementos da cultura como produtos comercializáveis e geradores de renda.

A presença indígena nas tecnologias de comunicação e informação é mais uma alternativa que foi apropriada dos não indígenas, para que o indígena fortaleça sua presença e pertencimento étnico.

\section{Referências}

BRASIL. Fundação Nacional do Índio. Quais os critérios utilizados para a definição de indígena? Disponível em: <http://www.funai.gov.br/index.php/todos-ouvidoria/23-perguntas-frequentes/ 97-pergunta-3>. Acesso em 10 fev. 2015.

HALL, S. A identidade cultural na pós-modernidade. Tradução Tomaz Tadeu da Silva e Guacira Lopes Louro. Rio de Janeiro: DP\&A, 2002.

HIPERMULHERES. Disponível em: <https://www.facebook.com/ashipermulheres $>$. Acesso em: 10 fev. 2015.

MATUK, A. Uma prospetiva política para um multiverso digivirtual: direitos humanos às tecnolinguagens In: SANTAELLA, L.; ARANTES, P. (Org.). Estéticas tecnológicas: novos modos de sentir. São Paulo: EDUC, 2011.

MESQUITA, C. Alargando as margens. In: MACHADO, A. (Org). Made in Brazil: três décadas do vídeo brasileiro. São Paulo: Itaú Cultural, 2003.

NICHOLS, B. Introdução ao documentário. Tradução Mônica Saddy Martins. Campinas, SP: Papirus, 2005.

PEREIRA, E. Ciborgues indígenas. br: a presença nativa no ciberespaço. 2008. Dissertação (Mestrado Estudos Comparados sobre a América) - Universidade de Brasília, Distrito Federal 2007.

UMA CASA, uma vida. Nova Xavantina, MT: Raiz das Imagens; Xavantes, 2013. 
Levantamento da presença indígena na internet e produção de mídias - outubro de 2014.

\begin{tabular}{|c|c|c|c|}
\hline \multicolumn{4}{|c|}{ REALIZADORES AUDIOVISUAL } \\
\hline $\begin{array}{l}\text { TAKUMÃ } \\
\text { KUIKURO }\end{array}$ & $\begin{array}{l}\text { Espero que vocês gostem destes filmes, 2007, } 10 \mathrm{~min} . \\
\text { Imbé Gikegü, Cheiro de pequi, 2006, } 36 \text { min. } \\
\text { Nguné Elü, O dia em que a lua menstruou, 2004, } 28 \mathrm{~min} . \\
\text { Eu já virei espírito, 2013, 18 min. } \\
\text { Kuikuro Kahehijü Ügühütu, O manejo da câmera, 2007, } 17 \text { min. } \\
\text { KIDENE - Academia Kuikuro }\end{array}$ & $\begin{array}{l}\text { Projeto de } \\
\text { formação }\end{array}$ & Kuikuro \\
\hline $\begin{array}{l}\text { DIVINO } \\
\text { TSEREWAHÚ }\end{array}$ & $\begin{array}{l}\text { Daritizé, Aprendiz de curador, 2003, } 35 \text { min. } \\
\text { Hepari Idub'rada, Obrigado Irmão, 1998, } 17 \text { min. } \\
\text { PI'ÕNHITSI, Mulheres Xavante sem nome, 2009, } 56 \text { min. } \\
\text { TSÕ'REHIPÃRI, Sangradouro, 2009, } 28 \text { min. } \\
\text { Vamos à luta!, 2002, 18 min. } \\
\text { Wai'á Rini, O poder do sonho, 2001, } 48 \text { min. } \\
\text { Wapté Mnhõnõ, Iniciação do jovem Xavante, 1999, } 56 \text { min. }\end{array}$ & $\begin{array}{l}\text { Projeto de } \\
\text { formação }\end{array}$ & Xavante \\
\hline $\begin{array}{c}\text { MARICÁ } \\
\text { KUIKURO }\end{array}$ & $\begin{array}{l}\text { Imbé Gikegü, Cheiro de pequi, 2006, } 36 \text { min. } \\
\text { Nguné Elü, O dia em que a lua menstruou, 2004, } 28 \text { min. }\end{array}$ & $\begin{array}{l}\text { Projeto de } \\
\text { formação }\end{array}$ & Kuikuro \\
\hline $\begin{array}{l}\text { NATUYU } \\
\text { YUWIPO } \\
\text { TXICÃO }\end{array}$ & $\begin{array}{l}\text { MARANGMOTXÍNGMO MÏRANG Das crianças Ikpeng para o } \\
\text { mundo, 2001, } 35 \mathrm{~min} \text {. } \\
\text { Moyngo, O sonho de Maragareum, 2000, } 42 \mathrm{~min} .\end{array}$ & $\begin{array}{l}\text { Projeto de } \\
\text { formação }\end{array}$ & Ikpeng \\
\hline $\begin{array}{l}\text { KUMARÉ } \\
\text { IKPENG }\end{array}$ & $\begin{array}{l}\text { MARANGMOTXÍNGMO MÏRANG Das crianças Ikpeng para o } \\
\text { mundo, 2001, } 35 \text { min. } \\
\text { Moyngo, O sonho de Maragareum, 2000, } 42 \text { min. }\end{array}$ & $\begin{array}{l}\text { Projeto de } \\
\text { formação }\end{array}$ & Ikpeng \\
\hline $\begin{array}{l}\text { KARANÉ } \\
\text { IKPENG }\end{array}$ & $\begin{array}{l}\text { MARANGMOTXÍNGMO MÏRANG Das crianças Ikpeng para o } \\
\text { mundo, 2001, } 35 \mathrm{~min} \text {. } \\
\text { Moyngo, O sonho de Maragareum, 2000, } 42 \mathrm{~min} . \\
\text { Pirinop - Meu primeiro contato, }\end{array}$ & $\begin{array}{l}\text { Projeto de } \\
\text { formação }\end{array}$ & Ikpeng \\
\hline
\end{tabular}




\section{REALIZADORES AUDIOVISUAL}

\begin{tabular}{|c|c|c|c|}
\hline \multicolumn{4}{|c|}{ REALIZADORES AUDIOVISUAL } \\
\hline $\begin{array}{c}\text { CAIMI } \\
\text { WAIASSÉ }\end{array}$ & 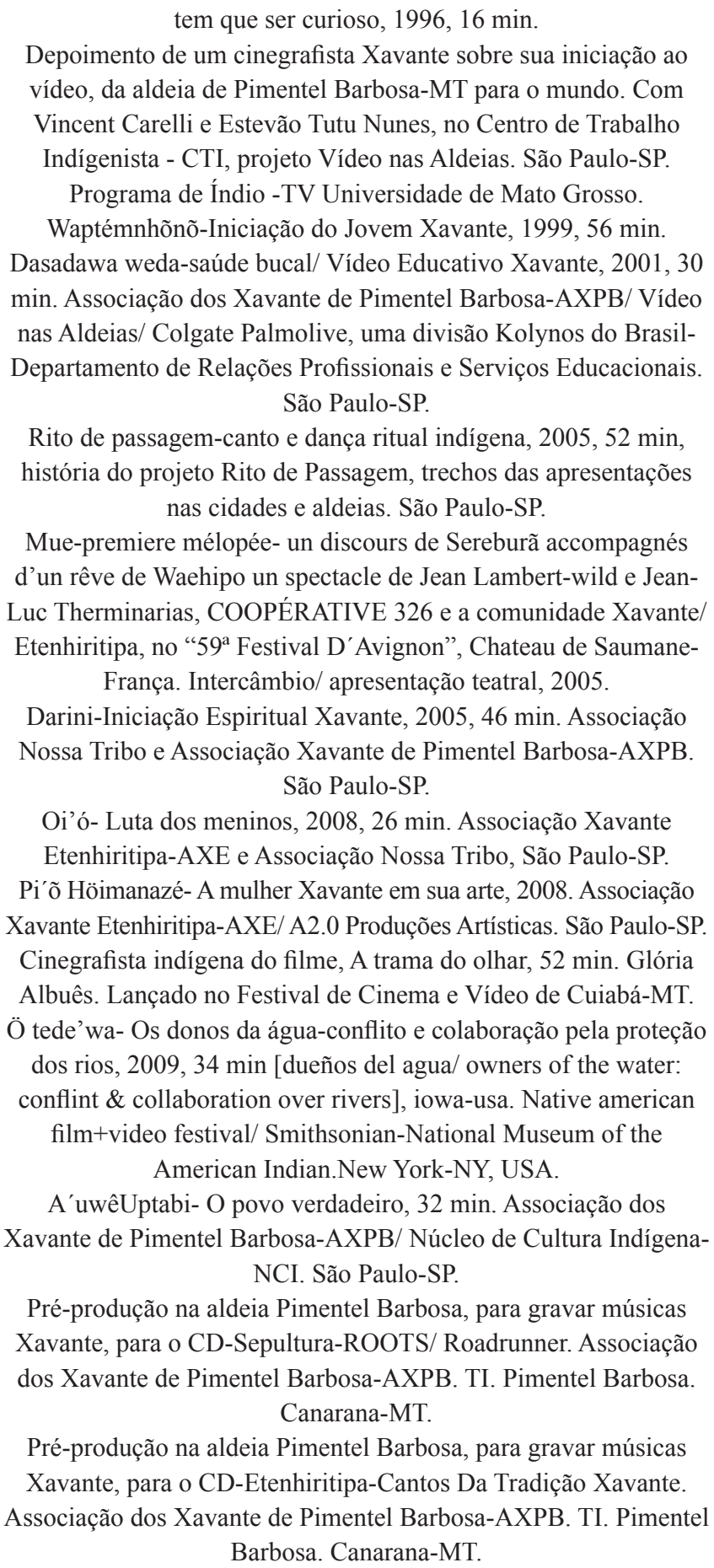 & $\begin{array}{c}\text { Projeto de } \\
\text { formação - } \\
\text { Universidades }\end{array}$ & \\
\hline Karané Ikpeng & Pirinop - meu primeiro contato & $\begin{array}{l}\text { Projeto de } \\
\text { formação }\end{array}$ & ikpeng \\
\hline $\begin{array}{c}\text { Coletivo } \\
\text { Xinguano }\end{array}$ & Nossa casa, uma vida & $\begin{array}{l}\text { Projeto de } \\
\text { formação }\end{array}$ & Xavante \\
\hline $\begin{array}{c}\text { Wisio } \\
\text { Kayabiayabiio } \\
\text { Kayabi }\end{array}$ & A história da cutia e do macaco & $\begin{array}{l}\text { Projeto de } \\
\text { formação }\end{array}$ & Kayabi \\
\hline
\end{tabular}




\section{REALIZADORES AUDIOVISUAL}

\begin{tabular}{|c|c|c|c|}
\hline Joao Kayoli & Vende-se pequi & $\begin{array}{c}\text { Coletivo Opan/ } \\
\text { Manoki }\end{array}$ & Manoki \\
\hline \multicolumn{4}{|c|}{ PÁGINAS NA INTERNET } \\
\hline Associa & dígena Associação Indígena Sapukuyawa Arakuni-AISA & $\begin{array}{l}\text { Coletivo } \\
\text { indígena }\end{array}$ & Waujá \\
\hline Organiza & os povos indígenas Xavante (OPIX) - Aldeia Sangradouro & $\begin{array}{l}\text { Coletivo } \\
\text { indígena }\end{array}$ & Xavane \\
\hline & Associação Kuikuro & Kuikuro & Kuikuro \\
\hline & ção Indígena Moygu Comunidade Ikpeng (AIMCI) & $\begin{array}{c}\text { Ikpeng e } \\
\text { instituto katitu* }\end{array}$ & Ikpeng \\
\hline & Associação Xavante Warã (MT)* & $\begin{array}{l}\text { X Coletivo } \\
\text { indígena }\end{array}$ & Xavante \\
\hline Instituto In & a Maiwu de Estudos e Pesquisas de Mato Grosso (Maiwu)* & $\begin{array}{l}\text { Coletivo } \\
\text { indígena }\end{array}$ & Vários \\
\hline & OPIX & Coletivo & Xavante \\
\hline & Página do indígena Bororo Felix Adugo & Individual & Bororo \\
\hline & Marawatsede & Não identificado & Xavante \\
\hline & Escola Estadual Kura Bakairi & Coletivo Bakairi & Bakairi \\
\hline \multicolumn{4}{|c|}{ PÁGINAS NO FACEBOOK } \\
\hline T.I. Kayal & tória indígena e resistência no Baixo Teles Pires (MT/ PA) & Não identificado & Kayabi \\
\hline & Centros de Memória Indígena Manoki & Não identificado & Manoki \\
\hline & Grupo dança indígena Manoki* & Não identificado & Manoki \\
\hline & Associação Watoholi* & Não identificado & Manoki \\
\hline & Produção de vídeos - Coletivo Xavante & $\begin{array}{c}\text { Xavante e } \\
\text { Empresa Raiz } \\
\text { das imagens } \\
\end{array}$ & Xavante \\
\hline & Ikaty Xingo & $\begin{array}{c}\text { Povos do Xingu } \\
\text { - ONGs }\end{array}$ & Xinguanos \\
\hline & Ipeax Xingu & $\begin{array}{c}\text { Não identificado } \\
\text { / Canarana }\end{array}$ & Xinguanos \\
\hline Art of the & zon indian collection-Colección de arte plumaria indígena & Não identificado & Vários \\
\hline & Projeto Malê & $\begin{array}{l}\text { Coletivo } \\
\text { Xavante } \\
\end{array}$ & Xavante \\
\hline & Umutina-Balatiponé e CIA limitada & $\begin{array}{l}\text { Coletivo } \\
\text { indígena }\end{array}$ & Umutina \\
\hline & Associação Terra Indígena Xingu - ATIX & $\begin{array}{l}\text { Coletivo } \\
\text { indígena }\end{array}$ & \\
\hline & Parentes unidos & $\begin{array}{l}\text { Coletivo } \\
\text { indígena }\end{array}$ & Vários \\
\hline & Aldeia Bakalana & $\begin{array}{c}\text { Aldeia Bakalana } \\
\text { / coletivo } \\
\text { indígena }\end{array}$ & Umutina \\
\hline
\end{tabular}

Fonte: Elaboração dos autores. 